\title{
Hume as a Trope Nominalist
}

\author{
J ani Hakkarainen \\ Discipline of Philosophy, School of Social Sciences and Humanities \\ Pinni B4134 \\ FI-33014, University of Tampere, Finland \\ jani.hakkarainen [at] uta.fi
}

\begin{abstract}
In this paper, I argue that Hume's solution to a problem that contemporary metaphysicians call "the problem of universals" would be rather trope-theoretical than some other type of nominalism. The basic idea in different trope theories is that particular properties, i.e. tropes are postulated to account for the fact that there are particular beings resembling each other. I show that Hume's simple sensible perceptions are tropes: simple qualities. Accordingly, their similarities are explained by these tropes themselves and their resemblance. Reading Hume as a trope nominalist sheds light on his account of general ideas, perceptions, relations and nominalism.
\end{abstract}

Keywords: Hume David, nominalism, tropes, metaphysics, ideas

\section{Introduction ${ }^{*}$}

Hume's account of general thinking in A Treatise of Human Nature, Book 1, part 1, section 7, is founded on "a resemblance among several objects” that "we have found” (T 1.1.7.7; SBN 20; cf. T 1.2.3.5; SBN 34). ${ }^{1}$ Put in terms of his theory of ideas, this account is founded on resembling perceptions, i.e. impressions and ideas. So Hume's view on general thinking cannot be really understood without understanding his explanation of resemblance between perceptions, about which Hume himself says very little. In this paper, my intention is to shed light on this issue by approaching it from the perspective of contemporary metaphysics. Much of current metaphysics is particularly concerned with a problem that is at issue in the foundation of Hume's account of general thinking: "the problem of universals". Tentatively, the problem of universals is a problem with how numerically distinct particular objects can resemble each other: either by having similar features or by sharing them (for example, the red colour of bodies). 
I will argue that, in contemporary terms, Hume's explanation of resemblance between perceptions should be described as a trope nominalist account rather than a predicate, concept, mereological, class or resemblance form of nominalism. ${ }^{2}$ The basic idea in different trope theories is that particular properties, called "tropes," are postulated to account for the similarity between particular objects. By contrast, the competing types of nominalism assume only objects, their relations and possibly some other kind of entities such as sets do this explanatory work. My view is that Hume's perceptions are understood better as particular properties than as objects (in this sense), and their resemblances are therefore essentially similarities between tropes. ${ }^{3}$ The clearest instance of this is provided by Hume's sensible simple perceptions, and their similarities. For the sake of brevity, I will restrict myself to arguing that they are tropes and leave complex perceptions and their properties for another paper. ${ }^{4}$

This paper has three parts. I will open it by outlining the problem of universals and the different solutions to it in contemporary metaphysics. This will lead me to the discussion of Hume's simple perceptions as tropes and their similarities. I will argue that these perceptions, which are always proper sensibles (visual, tactile, aural, olfactory, or gustatory), are tropes: primitives of Hume's theory and in themselves nothing but existing particular simple properties as qualities. ${ }^{5}$ The paper finishes with showing how my interpretation works as a reading of the ground of Hume's view of general simple ideas.

\section{The Problem of Universals and the Different Solutions to It}

There are actually two problems of universals discussed in contemporary metaphysics. One of them concerns kinds of things: what is the metaphysical explanation (ground) of belonging to a kind of particular objects? For example, what accounts for the fact that electrons belong to the natural kind "electron”? While this "problem of kind universals” is close to the medieval problem of universals, the other contemporary problem differs from the medieval problem sharply (Keinänen 2005, 102). This problem of universals is about properties of particular objects rather than their kinds. Unfortunately, metaphysicians disagree on its precise formulation. ${ }^{6}$ For the present purposes, though, the following formulation of the problem of universals is sufficient: which different categories of entities need to be postulated to account for the similarities between objects or their sharing of properties?

Trope nominalism is a promising solution to the problem of universals. Its various forms have been defended by D.C. Williams (1953a and 1953b), K. Campbell (1990), P. Simons (1994), 
A.-S. Maurin (2002), J. Heil (2003), M. Keinänen (2005 and 2011) and myself (Keinänen and Hakkarainen 2010, 2013). It accounts for the (exact) similarities between objects by means of tropes and their relation of resemblance. Tropes are particular properties. So, according to trope nominalism, there are not only particular objects such as electrons - as is assumed in the reist form of nominalism - but also properties that are particulars rather than universals. Usually, tropes are taken to be mereological atoms and qualitatively simple because they may be characterised in one way only (Maurin 2002, 121). A trope determines a single property of the object that possesses it. For example, a - $e$ charge trope determines a single property of an electron and is not composed of proper parts.

The trope-theoretical explanation of sharing properties may be described by an example. Trope theory accounts for the fact that electrons share $-e$ unit charge by saying that there are $-e$ charge tropes that are parts of electrons and related by resemblance. Resemblance is taken to be a primitive relation in the theory: its occurrences are not explained by other relations such as numerical identity between properties (realism) (Campbell 1990, 100ff.; Maurin 2002, 88ff.). In Keinänen's trope theory, it is also an ungrounded internal relation (Keinänen 2011, 439). Ungrounded internal relations are expressed by relational predications for the truth of which it is sufficient that their relata exist (in contrast to grounded internal relations that require something as a ground in their relata to exist and external relations that need conditions external to their relata to hold). However, they are not beings themselves: there are no such things as formal relations over and above their terms. In my example of electrons, the relational predication that two - $e$ charges are exactly similar is true in virtue of nothing but there being the two resembling $-e$ charge tropes without any relation of resemblance in itself existing in addition to the tropes. So an ungrounded internal relation, such as resemblance in Keinänen's theory, is a formal relation.

As a position that denies the existence of universals, trope theory is essentially different from any realist theory that postulates universals. I do not have to discuss realism here because Hume does not accept universals: multiply instantiated properties (T 1.1.7.6; SBN 19). So if he is not a trope theorist, his position must be some reist form of nominalism that postulates only particular objects and their relations, or a form that assumes objects, their relations and wholes/sums, classes or sets in order to solve the problem of universals. These alternative solutions in the contemporary literature are predicate, concept, mereological, class and resemblance nominalism (Armstrong 1978, 12-17). Here it is sufficient to discuss their key differences from trope theory. According to mereological, class and resemblance nominalism, particular objects, their (formal) relations and 
possibly wholes/sums, classes or sets are sufficient for explaining similarity. So they give a reductive explanation of the properties of objects: without certain (formal) relations, objects are "bare" of properties. Indeed, properties cannot be ontologically more fundamental than objects because sharing properties are accounted for by particular objects, which form the category of primitive entities. By contrast, in trope theory, properties are ontologically more fundamental as particular objects are composed of them. According to trope-bundle theory, objects are composed only of tropes, while a trope-substratum view assumes a substratum in addition to tropes.

In predicate and concept nominalism, the explanation of shared features is more semantic or conceptual than metaphysical (Armstrong 1978, 13-14). For two particular objects to share a feature $F$ is to fall under the same predicate or concept $F$ (two electrons falling under the predicate

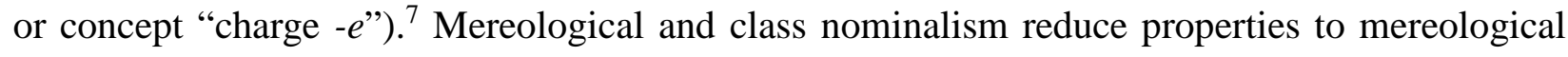
sums/whole and classes, respectively (Armstrong 1978, 15). According to the former, for electrons to share the property of $-e$ is for them to be parts of the same property -e sum/whole of particular objects, which is is a concrete particular entity. In class nominalism, the similarity in respect of charge is reduced to being the members of the same property class of - $e$ particular objects, which may be plurality or a set. On D. Lewis' version, in the case of perfectly natural properties, this does not cover only actual but also possible -e particular objects (1986, 50-53). These types of nominalism take parthood and membership as primitive, unanalysed notions. In resemblance nominalism, most aptly defended by Rodriquez-Pereyra (2002, 25), this primitive relation is resemblance. Its aim is to reduce having properties and sharing them to resembling objects (and their sets). The basic idea is that to have a property $F$ is to resemble all the $F$-objects. Sharing $F$ is then to resemble the F-particulars. Like Lewis, Rodriguez-Pereyra does not restrict this to actual particular objects: it concerns possible particular objects, too. Hence, if two electrons have the property $-e$ charge, the account says that the two electrons resemble all the actual and possible $-e$ particular objects and each other.

It is natural to assume that Hume must be either a mereological, class or resemblance nominalist because of the superficial appearance created by his account of general ideas in $\mathrm{T}$ 1.1.7.7ff. According to it, tentatively formulated, general ideas are parts, members or units of the sums/wholes, classes or sets of resembling ideas associated with a general name. For instance, the general idea of red is a part, member or unit of the sum/whole, class or set of red ideas associated with the word “red”. Don Garrett calls these classes or sets “revival sets” $(1997,106)$. Next I will argue that this appearance is misleading. I begin by showing that Hume's simple perceptions are 
tropes.

\section{Simple Perceptions}

\subsection{Tropes}

What are simple perceptions on Hume's account? He repeatedly says that they are "perfectly simple” (e.g. T 1.4.4.8; SBN 228). But what does he mean by it? He says surprisingly little about it and simple perceptions, which should form the basis of his account of the mind and cognition. He is, indeed, an empiricist who holds that perceptions are either simple or complex, which are composed of the simple (T 1.1.1.2; SBN 2). Anyhow, two things are therefore sure at least: simple perceptions are mereologically simple, i.e. they do divide into proper parts, and they are primitives of Hume's theory in the Treatise.

Otherwise we should follow the clue given by the type of simple perceptions, of which Hume says the most. Those are visual and tactile simple impressions and ideas. We may begin with their spatial simplicity. In themselves, separately from other perceptions, they appear spatially unextended. When only a single visual or tactile simple perceptions appears, it does not present even length. (T 1.2.1.4; SBN 27) Still these simple perceptions are capable of occurring in spatial relations and, indeed, composing spatial extension when they form complexes of a certain type ( $T$ 1.2.3.4-5; SBN 34-5). Other kind of simple perceptions cannot do this (T 1.4.5.9; SBN 235). In this respect, visual and tactile simple perceptions are "mathematical points": they appear as unextended points that are capable of spatial location and composing extension (T 1.2.2.9, 1.2.3.1213, 1.2.4.3 and 1.4.4.8; SBN 32, 38, 40 and 228). So visual and tactile simple perceptions are spatially minimal, spatial simples.

But this is not all and the following point is crucial. Hume is explicit that visual and tactile simple perceptions are not "bare"; on the contrary, they are "fill'd with something real and existent”: colours or tactile qualities such as temperature and hardness (T 1.2.4.2; SBN 39). They are, indeed, visual and tactile simple perceptions. It is not, as in resemblance nominalism for instance, that there are no properties without resemblance between objects. Rather, visual and tactile simple perceptions present qualities (properties) independent of resemblance. So simple perceptions in these sense modalities appear as coloured and tactile mathematical points when they are present separately.

Visual and tactile simple perceptions are not only spatially but also qualitatively simple. In Hume's case, qualitative simplicity and complexity should be put in terms of perceptual appearance 
or presentation rather than linguistic characterisation as perceptions are more fundamental than language. So the qualitative simplicity of visual and tactile simple perceptions means that in themselves they appear in only one way. Every coloured or tactile mathematical point is qualitatively uniform, i.e. presenting a single colour or tactile quality, navy blue, for example. That is the reason why Hume speaks about "a colour or solidity" in their case (T 1.2.4.3; SBN 40). One crucial point is that they are such even if they occur alone. Even if only one coloured mathematical point is present, it is something: it appears as something, i.e. as the colour. So visual and tactile simple perceptions may be described as self-presentations. They do not require any other entity to present colours or tactile qualities. A further point is that according to Hume's nominalism, every perception and every perception of a property is determinate: "the mind cannot form any notion of quantity or quality without forming a precise notion of the degrees of each” (T 1.1.7.3; SBN 18). He does not accept possibly Lockean indeterminate ideas. So visual and tactile mathematical points present a determinate tactile quality or shade of colour.

Presumably, other simple perceptions should follow this model even if they cannot be spatial and hence spatially simple. They are not bare; they self-present something. But are they qualitatively simple as well? It is not so obvious in their case as with coloured or tactile mathematical points. The latter are spatially minimal, there is no room for multiple manners of appearance in them, but the former are not restricted in this respect. Could they not present more than one quality, appear in more than one way? Could simple tastes not present more than one aroma? I believe Hume thinks they cannot and do not. This is so because of their mereological simplicity and his Separability Principle (SP).

As was seen just above, Hume thinks that every simple perception is a mereological atom. Usually, his talk about their perfect simplicity refers to this (T 1.2.4.4; SBN 40). Hume is also a representative of the view that qualities are parts, which is shown by his examples of the proper parts of complex perceptions: “a particular colour, taste, and smell” (T 1.1.1.2; SBN 2; cf. T 1.4.3.2; SBN 219). Thus, if simple perceptions were not qualitatively simple, i.e. single in their appearance, by the SP they should divide into proper parts. For whenever there is a real distinction, there is separability (Hakkarainen 2012, 61-62). But as simple perceptions do not divide into proper parts, they are also qualitatively simple: appear in one way only. ${ }^{8}$ Hume's simple perceptions present only a determinate shade of colour, tactile quality, sound, smell or taste. They are simple qualities. ${ }^{9}$

So far I have spoken about perceptions, mathematical points, qualities, properties and their appearances or presentations interchangebly. It might raise the question if I am conflating 
representations of mathematical points and properties with the mathematical points and properties. Are perceptions not representations of mathematical points and properties, rather than mathematical points and properties per se in the end? I think that would only misrepresent Hume's view. As I have argued so far, he thinks that simple perceptions are, in themselves, nothing but properties as qualities, visual and tactile of which are mathematical points. There are also passages that bear evidence for this as they are very hard, if not impossible, to account for without taking simple ideas as qualities. For instance, Hume says the following about the idea of space and those simple ideas that compose it: “in every repetition of that idea we wou'd not only place the points in the same order with respect to each other, but also bestow on them that precise colour, with which alone we are acquainted.” ( $\mathrm{T}$ 1.2.3.5; SBN 34) So actually the most exact way to put his view of simple perceptions would be to say: there is blue or a blue mathematical point, there is hot or a hot mathematical point, there is bitter, rather than, for instance, that there is a perception of blue. If one wants to speak about perceptions in this context, one should speak about a blue, hot or bitter perception. Hence, from this point on, I will speak about simple perceptions qualified by some quality, e.g., a red simple idea, rather than the simple perception of some quality when I am talking about determinate qualities.

A further crucial point for my interpretation is that every perception is a being, an entity for Hume. He is explicit about it:

"The only existences, of which we are certain, are perceptions, which being immediately present to us by consciousness [...] no beings are ever present to the mind but perceptions” (T 1.4.2.47; SBN 212).

It is important to understand, however, that this does not mean that Hume thinks that every perception has spatial existence. He does not require that as there are beings that are not in space:

"an object may exist, and yet be no where: and I assert, that this is not only possible, but that the greatest part of beings do and must exist after this manner. An object may be said to be no where, when its parts are not so situated with respect to each other, as to form any figure or quantity; nor the whole with respect to other bodies so as to answer to our notions of contiguity or distance. Now this is evidently the case with all our perceptions and objects, except those of the sight and feeling.” (T 1.4.5.10; SBN 235-6)

Thirdly, Hume goes so far as to claim that perceptions are the only conceivable existences. Even if this were an overstatement, it still strongly supports the interpretation that perceptions are beings:

"Let us fix our attention out of ourselves as much as possible: Let us chace our imagination to the heavens, or to the utmost limits of the universe; we never really advance a step beyond ourselves, nor can conceive any kind of existence, but those perceptions, which have appear'd in that narrow compass.” (T 1.2.6.8; SBN 67-8; cf. T 1.2.6.1-6; SBN 66-7) ${ }^{10}$ 
Now I think I have sufficient grounds to state that Hume's simple perceptions are tropes. Tropes are entities that are properties, particulars and qualitatively and mereologically simple. Every Humean perception satisfies the first condition for being a trope: it is an entity. Hume also holds that simple perceptions are nothing but self-presentations of qualities that are mereologically and qualitatively simple. Simple perceptions are not bare; they appear as properties independent of their resemblance relations (in contrast to the other metaphysical forms of nominalism). Visual and tactile simple perceptions have the further characteristic that they are spatial atoms. Perceptions, simple perceptions included, have also the categorical feature of tropes that they are particulars; Hume does not accept universals. In addition, Hume's simple perceptions are primitives of his theory because complex perceptions are composed of them. In this respect, Hume's view is isomorphic to trope theory, or to be precise, trope-bundle theory. Trope-bundle theories are onecategory ontologies: simple tropes form the sole fundamental category of entities. This means that entities of other categories, such as substances as trope-bundles, are explained by simple tropes and not vice versa.

\subsection{Objections and Resemblance}

Before moving on to resemblance between simple perceptions, I think I have to pause here for a moment. For I can almost hear in my mind numerous objections, from Hume scholars, to what I have just said. Doesn't the very simplicity of simple perceptions make them qualitatively complex: appearing in two ways at least? More generally, in the footnote to T 1.1.7.7 Hume says that simple ideas may have several points of resemblance. Doesn't this not make them qualitatively complex? What! Simple perceptions are "nothing but properties”. Are they not perceivings that consist of an act of perception and its object or content? Or alternatively, are they not states or dispositions of the mind or mental happenings rather than simply properties?

These are fair questions and I confess they make my view of Hume's simple perceptions controversial to some extent. They also raise big issues about Hume's account of the mind, perception and representation that cannot be exhaustively addressed in a short paper. Nevertheless, I can give some replies to these possible objections, starting with simplicity. It is an aspect that is not really distinct from the simple perception whose aspect it is. As I have argued elsewhere, the distinction between an aspect and a perception is a distinction of reason for Hume that requires the relation of resemblance between this perception and other perceptions (Hakkarainen 2012, 66, 68; cf. T 1.1.7.17-8; SBN 24-5). Whenever we consider the resemblances of a simple perception, we 
do not consider it in itself, separately from other perceptions. This is obvious from the fact that resemblance is a relation whose conception requires not only having the simple idea but also entertaining the other terms of the relation (more below). I cannot conceive that $a$ resembles $b$ if I conceive only $a$ but not $b$ (Hakkarainen 2012, 66). So in itself, a simple perception cannot present aspects, not even its simplicity (the case is the same with the pointness of visual and tactile simple perceptions). If there were only one simple perception, it would not be simple. Hence, the simplicity of a perception does not make it qualitatively complex: appearing in more than one way in itself.

There is also fairly conclusive textual evidence for this. Hume is explicit in the footnote that he appended to $\mathrm{T}$ 1.1.7.7 in the Appendix that the different points of resemblance do not make a simple idea complex: they do not introduce distinct qualities to it:

"'Tis evident, that even different simple ideas may have a similarity or resemblance to each other; nor is it necessary, that the point or circumstance of resemblance shou'd be distinct or separable from that in which they differ. Blue and green are different simple ideas, but are more resembling that blue and scarlet; tho' their perfect simplicity excludes all possibility of separation or distinction. 'Tis the same case with particular sounds, and tastes and smells. These admit of infinite resemblances upon the general appearance and comparison, without having any common circumstance the same. And of this we may be certain, even from the very abstract terms simple idea. They comprehend all simple ideas under them. These resemble each other in their simplicity. And yet from their very nature, which excludes all composition, this circumstance, in which they resemble, is not distinguishable nor separable from the rest. 'Tis the same case with all the degrees in any quality. They are all resembling, and yet the quality, in any individual, is not distinct from the degree.” (T 1.n.5; SBN 637) ${ }^{11}$

For the objection that Hume's simple perceptions are not mere properties but some more complex mental items such as perceivings, Donald C. Ainslie's (2008) reading is the most serious challenge. Ainslie has argued that Hume's perceptions are not only objects of mental acts but that they involve the mental act as awareness of the object, too. These mental actions are differentiated by the manner of awareness, whether it is seeing or thinking, for instance. He calls his account "the package view”. According to it, perceptions are packages that consist of a mental action and its content or object. The crucial point is that these constituents of the packages are not really distinct from each other and the package. Rather, they are its aspects. It seems to me that Ainslie's interpretation is not compatible with Hume's view that simple perceptions are qualitatively simple. Ainslie must concede that there are simple perceptions that appear in two ways even if they are considered separately from any other perception: as having some content and awareness of that content. For instance, if a simple perception is visual, on Ainslie's account it appears not only as a content but also as a seen content. However, this cannot be a Humean doctrine since then this 
simple perception would not be qualitatively simple but complex. ${ }^{12}$

Now it is time to turn to Hume's account of resemblance. Resemblance belongs to the first category of Hume's dichotomy of relations, whose perceptions are always complex (T 1.1.4.7, 1.1.5.1; SBN 13). Its idea depends solely on the related ideas: given the ideas that are the relata ideas, there must also be the an idea of the relation, too (T 1.3.1.1-2, 1.3.3.3; SBN 69-70, 79-80). By contrast, the other category, causation, for instance, needs relata-external circumstances to hold (T 1.3.2.2; SBN 73-4). So for Hume, to use contemporary parlance, resemblance is an internal relation, whereas causation is an external relation. For example, if there are two red simple ideas present to the mind, then they resemble each other. Or, if a resemblance between simple ideas appears, there must be also the particular resembling simple ideas.

When this is extended to concern impressions of relations, we can see that Hume understands an important characteristics of the resemblance relation between tropes very well: it is Keinänen calls an "ungrounded" rather than a "grounded" internal relation. The occurrence of its simpleperception terms in the mind is sufficient for its occurrence; it does not require any further ground in the terms to hold (recall that simple perceptions are nothing but properties and they do not divide into proper parts). ${ }^{13}$ Rather, the terms themselves are the ground for the resemblance. This is shown by the footnote at $\mathrm{T}$ 1.1.7.7, which I quoted above, where Hume argues that the grounds, the points or circumstances of resemblance relations between simple ideas are not separable from these simple ideas. Rather, they are the simple ideas themselves. This point is crucial for trope nominalism as it makes it possible that tropes may bear different resemblance relations without being qualitatively or mereologically complex.

\section{Conclusion: Hume's Account of Simple Perceptions Being Similar}

Finally, we are in the position to pose the problem of universals to Hume: how does he explain shared properties between two simple perceptions? His explanation is straigthtforward: shared properties reduce to a similarity between the two simple perceptions. That similarity, in turn, is accounted for by these simple perceptions themselves and their ungrounded internal relation of resemblance. For example, if the two simple perceptions are navy blue, their sharing the property of navy blue is simply that they are navy blue qualities that happen to resemble each other. That the two simple perceptions, which are tropes, are present to the mind is also sufficient for this resemblance. Indeed, in trope nominalism, resemblances between tropes - whatever they are follow from the mere existence of the tropes (the terms of the resemblance relations); there is no 
further explanation for their occurrence. By contrast, in resemblance nominalism, resemblance relations between objects account for having properties and sharing them. Thus, Hume's account in terms of simple perceptions clearly represents a trope-theoretical account even if resemblance is not a perception-independent relation as it is in trope theories. This is only natural, however, as I am speaking about perceptions of resemblance here - Hume's account is perception-dependent

It may be objected to this that Hume's view is not eventually trope nominalist but some other nominalist account because he (in)famously argues that simple perceptions are substances due to their existential independence ( $\mathrm{T}$ 1.4.5.5; SBN 233-4). Indeed, Armstrong claims that tropes are “junior substances" in the accounts that take them as existentially independent (1989, 115; cf. Campbell 1990, 15-16, 21). However, Hume's position is not some rival type of nominalism for a simple reason. Even if simple perceptions are "junior substances”, they are simple qualities: in themselves they present only a determinate shade of colour, tactile quality, sound, smell or taste. Hume does not explain simple properties by resemblance relations between objects, but postulates them in order to account for sharing of the properties of simple perceptions.

In the introduction, I promised that trope nominalism can shed light on the foundation of Hume's account of general ideas. Now it is time to fulfil that promise. Let me take the example of navy blue. What is the foundation of Hume's account of this general idea? According to my tropetheoretical interpretation, the foundation is the plurality of navy blue ideas that resemble each other. In themselves, independent of their resemblance, these ideas appear as navy blue. They resemble because they present navy blue. This plurality of navy blue ideas consists of both simple navy blue ideas and complex ideas that have one or more simple navy blue ideas as their constituents. The general term "navy blue" corresponds to any of these navy blue ideas. They are all particular and determinate but "general in their representation" in virtue of their resemblance (T 1.1.7.6; SBN 20). Any of them can serve as the general idea of navy blue.

Notes on contributor: Jani Hakkarainen received my PhD from the University of Tampere, Finland in December 2007. The topic of his dissertation was Hume's scepticism with regard to the senses. During his post-doc years, he has been studying metaphysics, both contemporary and Hume's. Currently, he is a Post-doctoral Fellow in philosophy at the University of Tampere. 


\section{References}

Ainslie, Donald C. 2008. “Hume's Perceptions.” Paper presented at the 35th Annual Hume Society Conference, Iceland, August 6-10.

Armstrong, D. M. 1978. Nominalism \& Realism: Universals and Scientific Realism. Cambridge: Cambridge University Press.

Armstrong, D. M. 1989. Universals: An Opinionated Introduction. Boulder, CO: Westview Press.

Armstrong, D. M. 1997. A World of States of Affairs. Cambridge: Cambridge University Press.

Campbell, K. 1990. Abstract Particulars. Oxford: Basil Blackwell.

Garrett, Don. 1997. Cognition and Commitment in Hume's Philosophy. Oxford: Oxford University Press.

Devitt, Michael. 1997. “'Ostrich Nominalism' or 'Mirage Realism'?’ In Properties (originally published in Pacific Philosophical Quarterly 61: 433-449), edited by D.H. Mellor and Alex Oliver, 93-100. Oxford: Oxford University Press 1997.

Hakkarainen, Jani. 2012. “A Third Type of Distinction in the Treatise.” Hume Studies 38 (1): 55-78.

Heil, John. 2003. From an ontological point of view. Oxford: Oxford University Press.

Hume, David. 2007. A Treatise of Human Nature: A Critical Edition. 2 vols. Edited by David Fate Norton and Mary J. Norton. Oxford: Clarendon Press.

Hume, David. 1975. A Treatise of Human Nature. Edited by L. A. Selby-Bigge, revised by P. H. Nidditch. 2nd ed. Oxford: Clarendon Press.

Hume, David. 1932. Letters. Vol. 1 of The Letters of David Hume. Edited by J.Y.T. Greig. Oxford: Clarendon Press.

Keinänen, Markku. 2005. Trope Theories and the Problem of Universals. Helsinki: University of Helsinki Press.

Keinänen, Markku. 2011. “Tropes - The Basic Constituents of Powerful Particulars?” Dialectica 65 (3): 419-450.

Keinänen, Markku and Jani Hakkarainen. 2010. "Persistence of Simple 
Substances.” Metaphysica 11 (2):119-135.

Keinänen, Markku and Jani Hakkarainen. 2013. “The Problem of Trope Individuation: A Reply to Lowe.” Erkenntnis online first. doi: 10.1007/s10670-013-9459-y.

Lewis, David. 1986. On the Plurality of Worlds. Oxford: Blackwell.

Lowe, E. J. 2006. The Four-Category Ontology. Oxford: Oxford University Press.

Maurin, Anna-Sofia. 2002. If Tropes. Dordrecht: Kluwer Academic Publishers.

Rodriguez-Pereyra, Gonzalo. 2002, Resemblance Nominalism. A solution to the problem of universals. Oxford: Clarendon Press.

Simons, Peter. 1994. "Particulars in Particular Clothing - Three Trope Theories of Substance.” Philosophy and Phenomenological Research 54 (3): 553-575.

Williams, Donald Cary. 1953a. “On the Elements of Being: I.” Review of Metaphysics 7 (1): 3-18.

Williams, Donald Cary. 1953b. “On the Elements of Being: II.” Review of Metaphysics 7 (2): 171-192.

* Writing this paper was made possible by the funding of the Academy of Finland.

1 References to Hume's Treatise are to (2007), hereafter cited as “T” followed by Book, part, section, and paragraph numbers; and to (1975), hereafter cited as "SBN" followed by page number.

2 In the future, I hope that the trope-theoretical account of Hume's metaphysics can be extended to his account of the composition of bodies and minds, their identity and causation.

3 Consequently, the paper is not motivated only by understanding the basis of Hume's account of general perceptions. It can also shed light on the issue what his perceptions are, which is too much neglected a topic in Hume scholarship (Ainslie 2008).

${ }_{4}^{4}$ Usually, Hume does not speak about properties but of qualities and quantities. However, there are exceptions (e.g. T 1.2.2.4, 1.2.4.21, 1.2.4.26, 1.3.5.3, 1.4.7.7, and n.12; SBN 31, 46-47, 49-50, 85, 267-268 and 638-639). So it is not unjustified to use it in describing Hume's thinking. Today, a property is sometimes taken to mean an universal but there is a use of it that is neutral on the divide between universals and particulars (Lowe 2006, 70). This use is in the categorial distinction between objects and properties.

${ }^{5}$ I set simple perceptions of bodily feelings and passions aside as they are not properties. Henceforth, I will drop the attribute "sensible”, unless otherwise noted.

${ }^{6}$ G. Rodriquez-Pereyra (2002, 28) and A.-S. Maurin (2002, 61), for instance, take it as a problem about truth-making: the task is to find truth-makers for true propositions that indicate that certain particulars have common properties. By contrast, M. Keinänen has argued (2005, 98-107), following D. M. Armstrong (1978, 41), that the problem is about formal ontology: which category system accounts for the (exact) 
similarity of the lowest determinates of certain determinables best by some standards. For example, according to physics, it is an objective fact that every electron (particular object) exactly resembles every other electron in respect of charge (determinable), i.e. having the unit charge -e (lowest determinate). What is the best category system to ground this fact metaphysically?

Ostrich nominalism (Devitt 1997 [1980]) is close to predicate nominalism but the former denies that there is any metaphysical problem to be explained. So it does not have to be discussed in this paper.

${ }^{8}$ Still this does not rule it out that simple perceptions can have aspects when the latter are not taken to be really distinct from the former.

9 The qualitative simplicity of simple perceptions is supported by what Hume says about passions that are simple perceptions:

“The passions of pride and humility being simple and uniform impressions, 'tis impossible we can ever, by a multitude of words, give a just definition of them, or indeed of any of the passions.” (T 2.1.2.1; SBN 277)

“ 'Tis altogether impossible to give any definition of the passions of love and hatred; and that because they produce merely a simple impression, without any mixture or composition.” (T 2.2.1.1; SBN 329)

${ }^{10}$ It would also be hard to see how Hume could hold a bundle theory of the mind if the perceptions that compose the mind did not exist.

${ }^{11} \mathrm{Cf}$. "The Word, simple Idea, is an abstract Term comprehending different Individuals that are similar. Yet the point of their Similarity from the very Nature of such Ideas is not distinct nor separable from the rest. Is not this a Proof, among many others, that there may be a similarity without any possible Separation in thought?” (Letter of 16 March 1740 to Hutcheson, Hume 1932, 38-39)

${ }^{12}$ Ainslie also argues that the object view, which is close to my reading, cannot account for force and vivacity. But he overlooks the possibility of a functionalist account: nothwithstanding Hume's phenomenal language, force and vivacity/liveliness refer to the functional role that perceptions play in their system. Unfortunately, I cannot spell out this account here because of the word limit.

${ }^{13}$ This gives additional support for my argument above that the simplicity of simple perceptions does not make them qualitatively complex. Take a blue simple perception. It may be said to be simple as it exactly resembles other simple perceptions. Resemblance is an ungrounded internal relation. Ungrounded relations do not require any ground in their terms (vs. grounded): the mere occurrence of the terms is sufficient for the relation to hold. Hence, the fact that it holds between the blue simple perception and other simple perceptions does not introduce features or aspects to the blue simple perception that would be really distinct from it and serve as the ground for the relation of resemblance. 